\title{
La pregunta por el sentido de la religión en la actualidad. Una reflexión en torno a lo esencial de la religión
}

\author{
The question of meaning of religion in current times. \\ A reflection on the essence of religion \\ Roxana Osses Valle \\ Facultad de Ciencias Religiosas y Filosofía \\ Universidad Católica de Temuco-CHILE \\ roxana.osses@uct.cl
}

\section{Resumen}

La pregunta por el sentido que otorga la religión en la actualidad dentro de un contexto de crisis institucional, es una pregunta necesaria no sólo a nivel religioso sino también social. El desarrollo de ésta, posibilita analizar las comprensiones que existen en la actualidad respecto de la experiencia religiosa. Asumir la pregunta por el sentido de la religión desde una perspectiva creyente, permite replantear ciertos presupuestos básicos que son comunes a toda religión, de modo que se puedan utilizar como criterios de discernimiento en la búsqueda de una praxis religiosa coherente.

Palabras clave: sentido, religión, crisis institucional, encuentro, fe, cristianismo

\begin{abstract}
The question about the meaning that religion currently grants in a context of institutional crisis is a necessary question not only on a religious level but also on a social level. Its development makes it possible to analyze the understandings that currently exist regarding religious experience. Assuming the question about the meaning of religion from a believer perspective, allows us to rethink certain basic presuppositions that are common to every religion, so that they can be used as criteria of discernment in the search for a coherent religious praxis.
\end{abstract}

Keywords: meaning, religion, institutional crisis, finding, faith, christianity

Recibido: 18 de Octubre de 2019 - Aceptado: 12 de Diciembre de 2019

Roxana Osses Valle

La pregunta por el sentido de la religión en la actualidad. Una reflexión en torno a lo esencial de la religión. Autoctonía. Revista de Ciencias Sociales e Historia, Vol. IV, N 1 , Enero-Junio 2020, 91-112

ISSN 0719-8213

DOI: http://dx.doi.org/10.23854/autoc.v4il.155 


\section{Introducción}

La religión ha sido fuente de sentido para la existencia del hombre desde tiempos remotos, sin embargo, nos encontramos en un momento histórico donde la comprensión de religión ya no es obvia y donde la idea predominante es que ella ha dejado de dar sentido en la sociedad actual. Esta idea prevalece en contextos de crisis institucional y de resquebrajamiento de las estructuras eclesiales por su evidente praxis que distorsiona a la religión, consecuencia de ello, una gran mayoría de creyentes han optado por tomar distancia y vivir su fe en un espacio privado dejando por completo la vida litúrgica en comunidad, mientras que otra gran mayoría, ha comenzado a organizarse desde sus comunidades de base para buscar nuevas formas de vida eclesial, guiados por las mociones del Espíritu del resucitado.

En este escenario, parece oportuno despejar la comprensión de religión que existe en la actualidad: por una parte, para develar que, en muchas ocasiones dichas comprensiones de religión no otorgan sentido a la existencia del hombre y la mujer actual, porque en sus comprensiones y praxis se entretejen dinámicas de distorsión de la experiencia religiosa; y, por otra parte, está la posibilidad de acoger algunos criterios de discernimiento que se han planteado desde el pensamiento teológico-filosófico, como ha sido el aporte de Welte (1984) 1 para reconocer que, a pesar del contexto de crisis actual, se puede vivir una religión que otorga sentido a la existencia del ser humano. Desde esta perspectiva, gran parte del pensamiento se desarrolla desde una visión cristiana teniendo presente ciertas comprensiones que integran a otras religiones.

En esta línea, en un primer momento, se contextualizará la comprensión de sentido y de religión. Luego, se desarrollarán las posibilidades en las que la religión puede otorgar sentido a través de tres aspectos esenciales de ésta. Por último, se plantea de modo sintético algunas perspectivas y desafíos.

\section{La Pregunta por el Sentido de la Existencia, una Pregunta Fundamental}

En primer lugar, nos interesa tener un acercamiento a lo que se comprende por sentido ${ }^{2}$, o por lo menos mencionar algunas de las principales significaciones, para luego desarrollar desde dónde se comprende que la religión otorga o no sentido a la existencia del hombre y la mujer en la actualidad (Martínez y Cortés, 1996).

"Hablar del sentido (significado) de una palabra, del sentido (orientación de la dirección) de una fuerza, del sentido de un acto voluntario o de una vida, es en rigor, hablar de cosas muy dispar" (Ferrater, 1958: 1220.); pero a pesar de su significación dispar, hay una unidad en sus manifiestos ${ }^{3}$, ya sea desde una perspectiva metafísica ${ }^{4}$ o fenomenológica ${ }^{5}$, como también desde una perspectiva que considera el sentido como una dirección ${ }^{6}$ (Ferrater, 1958). Así, al mencionar alguno de los principales autores en este pensamiento respecto del sentido, tenemos entre otros a Husserl, Lask, Cassirer y Hofmann, para ellos: 
Sentido en tanto que sentido expresado por la expresión a la unidad que cubre tanto la significación de ella. Emil Lask insiste en el aspecto total-axiológico de sentido, el cual correspondería únicamente a elementos estructurales. Para Cassirer, el sentido pertenece en sus primeros comienzos míticos a la esfera de la existencia; el sentido sería entonces algo substancial, un ser o una fuerza, y en vez de limitarse a apuntar a un contenido sería el mismo contenido. Para Paul Hofmann, el sentido se comprende sobre todo en función de lo histórico. Según Robert Schinzinger, la esencia y la realidad se caracterizan, a su entender, por medio de su específica relación significativa (Ferrater, 1958: 1222).

En nuestras primeras aproximaciones al tema, constatamos que el sentido7, comienza a tener preponderancia en la discusión filosófica y social desde la segunda mitad del siglo XX. Es por eso que, la pregunta por el sentido:

Ha desplazado en alguna medida a las clásicas de la metafísica (ser), de la antropología (verdad), de la teología (salvación), como si lo que el ser humano necesita trascendiera cada uno de esos campos, por ser algo más fundamental, abarcante, radical (Gesché, 2004: 9).

Por lo tanto, la pregunta por el sentido de la vida es una pregunta fundamental de la existencia, es decir, no es una pregunta opcional o circunstancial, ya que el hombre no puede dejar de preguntarse por el sentido de su existencia, porque éste, finalmente tiene que ver con el interés con el cual el hombre se mueve y existe en el mundo. Por lo mismo, Gesché (2004) cita a González de Cardedal, quien define sentido como aquello que:

crea el ámbito necesario para respirar con holgura, para existir sin sobresalto, para avanzar confiados hacia el futuro, para asumir la vida en propia mano, para confiar en que el empeño de nuestros días no será vano ni nuestro amor cenizas (p. 9).

Entonces, uno de nuestros primeros elementos que recogemos para nuestra comprensión de sentido es que, éste deviene del hombre, es decir, el hombre es una constante pregunta sobre el sentido de la existencia: “Querámoslo o no, observa Pascal en su Apuesta, todos estamos “embarcados": ¿en qué somos?, ¿para qué existimos?, ¿a dónde vamos? El hombre no puede eliminar estas preguntas sin renunciar a ser hombre" (Latourelle y Fisichella, 1990: 1356). En esta misma perspectiva, Welte (1984), propone que, el sentido es parte de la estructura fundamental del hombre porque éste tiene que ver con la significatividad con la que el hombre se mueve en su existencia. La significatividad para este autor, es el interés con el que el hombre se mueve y existe en relación al mundo, lo plantea con el término "Weltdasein" que quiere decir "estar ahí en el mundo"8, con sentido (Martínez y Cortés, 1996; Pacomio, 1983).

\section{La Comprensión de Religión}

En este segundo apartado, reflexionaremos sobre cómo la religión es posibilitadora de sentido para la sociedad actual a partir de un aspecto general 
de la religión, que, luego nos permitirá profundizar en algunos de los aspectos centrales de la religión cristiana.

Comenzamos nuestra exposición aclarando que, con el hecho de referirnos al término general de religión ${ }^{9}$, sin lugar a dudas, se nos viene a la mente un recorrido histórico de la humanidad, cargado de símbolos, culturas, ritos, creencias y visiones respecto de Dios y del hombre en relación a Él, constatando que la cantidad de pensamiento sobre ello es innumerable. Por lo mismo, cuando nos referimos al ámbito de la religión, sabemos que se trata de todo un mundo complejo de experiencias religiosas, décadas de historia de las diferentes religiones, investigaciones, hallazgos arqueológicos, diccionarios especializados, estudios monográficos, estudios de la religión desde perspectivas interdisciplinarias ${ }^{10}$, entre muchos otros estudios, que nos permiten observar que la religión hoy día se estudia desde perspectivas especializadas. Es por eso que, en la actualidad, al momento de hablar de religión, significa en primer lugar, identificar el ámbito desde el que se desarrolla el pensamiento, ya que de ello dependerá el aspecto de religión que se expone, las herramientas de investigación que se utilizan, que determinarán también el lenguaje con el cual se expone dicho pensamiento. En este artículo desarrollaremos el pensamiento desde una perspectiva teológico- filosófica (Latourelle y Fisichella, 1990).

Luego, continuamos exponiendo que, la dimensión religioso o espiritual en el ser humano, es una dimensión que se encuentra dentro del conjunto de dimensiones que ha desarrollado el ser humano históricamente como lo es la dimensión personal, social, política, cultural y económica. Esto, debido a que el ser humano en sí, ontológicamente se define como un ser espiritual, pues, los numerosos estudios interdisciplinarios han arrojado que el fenómeno religioso, es una dimensión antropológica universal expresada en la historia, desde los orígenes más primitivos: "En estos contextos culturales originarios encontramos ya vestigios prehistóricos de creencia en un más allá con características animistas"11 (Santidrián, 1993, p.392). De la misma forma, la conciencia humana de la propia inconsistencia determina las diversas formas de ritos mágicos. Así, después de un largo recorrido histórico de la humanidad respecto del desarrollo religioso, se reconocen desde la filosofía de la religión por lo menos a cinco religiones como las principales: de las religiones semitas: el Judaísmo ${ }^{12}$, el Cristianismo ${ }^{13}$, y el Islam ${ }^{14}$ y luego, en las religiones del extremo oriente: el Hinduismo ${ }^{15}$, y el Budismo ${ }^{16}$ (Bentué, 2004).

Así también, reconociendo la diversidad de formas religiosas, se puede observar de fondo ciertas estructuras significativas comunes a todas las religiones. A partir de ello, se han realizado estudios, por ejemplo, desde la fenomenología de la religión, que permiten observar cuatro rasgos primordiales que son comunes a toda religión y que para efectos de nuestro estudio nos parece pertinente mencionarlos.

Dentro de estas estructuras significativas en común a todas las religiones, encontramos en primer lugar, el ámbito de lo sagrado17. Una de las principales características del ámbito de lo sagrado es que se trata de: "Un mundo en que el 
sujeto se introduce tras el paso de un umbral. Este paso exige del sujeto una ruptura de nivel [...] El umbral de lo sagrado separa el mundo religioso de la vida ordinaria" (Floristán, 2002: 1252). Ello no significa vivir de dos mundos, sino que vivir la vida ordinaria, después de aquella experiencia con lo sagrado, pero de un modo completamente nuevo. En este sentido, es interesante que algunos fenomenólogos de la religión recogen una distinción que realizan éstas religiones en sus diferentes sistemas de creencia que tiene relación entre el mundo profano y el mundo de lo sagrado, esto, debido a que lo sagrado en el mundo es comprendido como lo definitivo, lo único que tiene real importancia.

En segundo lugar, está la dimensión del misterio18; es el misterio lo que determina la aparición de lo sagrado. Su primera característica es su absoluta trascendencia ${ }^{19}$, pero también aparece el misterio como la perfecta inmanencia, en la perspectiva de que esa realidad trascendente que llamamos Dios, se presenta cercano al ser humano. Por ejemplo, San Agustín decía al respecto que, Dios es más próximo al hombre que su propia intimidad (interior intimo meo) (Arocena, Burggraf e Izquierdo, 2006).

Con estos dos rasgos mencionados, respecto de la realidad omniabarcante, a saber, el misterio y lo sagrado; da cuenta que, como estructura fundamental a todas las religiones, es Dios quien se manifiesta al hombre, tomando la iniciativa. Gracias a ello, el sujeto puede entrar en comunión con Dios, traduciéndose luego cada religión con un estilo, un lenguaje socio-cultural y socio-religioso propio de cada contexto geográfico.
En tercer lugar, encontramos la dimensión de la actitud religiosa ${ }^{20}$, que es la respuesta del hombre a la manifestación del misterio que conocemos con el nombre de Dios (Arocena, Burggraf e Izquierdo, 2006). "El sujeto debe responder de una forma bien precisa [...] en una actitud religiosa fundamental que consiste en su esencia en un doble movimiento que contiene el total trascendimiento de su plena salvación” (Floristán, 2002: 1254).

La dimensión religiosa es parte constitutiva del ser humano:

El hombre es invitado al diálogo con Dios desde su nacimiento, pues no existe sino, porque creado por amor, es conservado siempre con amor; y no vive plenamente según la verdad si no reconoce libremente aquel amor y se entrega a su creador. (G. S. 9)

En cuarto y último lugar, para terminar de mencionar los principales rasgos del fenómeno religioso, se encuentran las mediaciones en que se hace presente el misterio. En palabras de fenomenólogos, estas expresiones son denominadas: Hierofanías $^{21}$ (Eliade, 1982). Estas expresiones tienen tres grupos principales que caracterizan a la familia de las religiones: "como lugar hierofánico principal, la naturaleza; luego, la historia y los acontecimientos en que se realizay, por último, la misma persona humana, sus funciones y acciones más importantes" (Floristán, 2002: 1258).

Es así que, luego de mencionar a modo muygeneral algunos rasgos fundamentales que comportan el ámbito de la religión, vamos a continuar ahora nuestro itinerario, planteando los presupuestos 
que permiten al ser humano la apertura a Dios como experiencia de sentido desde la religión.

\section{La Religión Como Propuesta de Sentido a Través de una Experiencia Vital}

En este apartado se desarrollará bajo tres aspectos esenciales las posibilidades en las que la religión como tal otorga sentido a la existencia del ser humano.

\subsection{El sentido de la religión desde la experiencia vital del Encuentro}

Una de las expresiones religiosas que nos permite observar el acontecimiento del encuentro del ser humano con Dios, es la oración ${ }^{22}$ (Arocena, Burggraf e Izquierdo, 2006). Welte (1984), la define como "el acto vital de conversión a Dios" (p.30), enunciando tres modos que son esenciales a cualquier modo de oración, a saber: la oración en forma de silencio, la oración en forma de lenguaje y la oración litúrgica.

Como ya lo mencionábamos anteriormente, la comprensión sobre religión viene dada por el modo en que el ser humano se comporta y habla con Dios; este modo de comportarse tiene que ver con una respuesta del ser humano a la manifestación de Dios, ya que, si Dios no se manifestara al hombre, éste no tendría interés en conocerlo y comunicarse con Él.

Para Welte (1984), "Dios es el que primeramente se comporta con el hombre, eso tiene lugar dentro del comportarse del hombre, dentro de la existencia humana y de su propia inteligencia" (p.31). Por eso, define la religión como una forma de existencia humana, ya que ella es expresión del encuentro de Dios con el hombre a modo humano. Y este encuentro vital "brota de una experiencia humana, original y primaria, de relación con una realidad suprema, a la que denominaremos misterio, que confiere sentido a la propia vida, a la vida social, y a la vida histórica" (Arocena, Burggraf e Izquierdo, 2006: 848).

La experiencia de encuentro entre el ser humano y Dios, es la experiencia más originaria de la religión, y como experiencia de encuentro que responde a los anhelos más hondos del ser humano aporta sentido a su existencia. Por eso, podemos hablar de una dimensión religiosa que es significativa para la existencia humana de modo particular, a tal punto, que cuando el creyente experimenta y profundiza ese encuentro con Dios, como respuesta gratuita nace una actitud de fe, de plena confianza en esa experiencia. Así, la significatividad se constata en la medida en que ese acontecimiento particular del hombre que busca sentido, se encuentra con una respuesta concreta en la manifestación de Dios. Entonces constatamos que: "a partir de Dios la existencia del hombre se descubre en su dimensión religiosa" (Welte, 1984: 32).

Al respecto, es importante mencionar que, este encuentro es constantemente determinado por el contexto histórico y sociocultural, pues, es en la historia concreta en que Dios es mensaje y contenido para el creyente. Este mensaje y contenido, por ejemplo; en el cristianismo tiene su culmen en la persona de Jesús de Nazareth. Dios se revela en su Hijo, en la dinámica del ocultarse y 
mostrarse en dirección directa al ser humano y a modo humano en la persona de Jesús de Nazareth. Por eso, Jesús es mensaje y contenido de salvación para el hombre:

El asunto mismo que se revela como mensaje e interpretación es llamado en los libros del Nuevo Testamento con preferencia, Reino de Dios, o gracia de Dios, o salvación [...] Se trata entonces de afirmar al ser humano, de darle plenitud, de elevarlo, desde Dios. La revelación cristiana es Revelación de la salvación divina (Welte, 1984: 48).

Dios que se revela al hombre en su Hijo, Jesús de Nazareth, lo hace de un modo completamente histórico, por eso los cristianos, en la celebración del misterio pascual, recuerdan la gran experiencia de Dios con los hombres que marca todo tiempo: "[...] cómo toda la salvación en el despliegue de todo tiempo y espacio ha acontecido en un sólo instante de la historia, quedando indisolublemente asociada a ella, de cómo esta historia da sentido a toda historia" (Silva, 2011:544). Así, la historia tiene un sentido único por la encarnación de Dios en su Hijo Jesucristo (Jn. 1,1-14). Y en cuanto es mirada a la luz de dicho acontecimiento, se comprende la propia existencia a la luz de "de Dios con nosotros", es decir, el Emmanuel (Mt. 1,23). Por lo mismo, la Iglesia Católica, ha reflexionado a través de la historia sobre este gran acontecimiento en innumerables ocasiones, a través de diversos concilios, como el concilio de Nicea I, Éfeso, Calcedonia, Constantinopla, Letrán, Trento, Vaticano I y Vaticano II. Discutiendo y afirmando así, la auténtica doctrina sobre la revelación y su transmisión: "Para que todo el mundo, con el anuncio de la salvación, oyendo crea, y creyendo espere, y esperando ame” (D. V. 1).

\subsection{El silencio una experiencia fundamental de sentido en la religión}

La oración del silencio, aparece como respuesta a la inefabilidad de Dios; en ella se revela de fondo que el hombre ha experimentado a Dios en su inefabilidad, que es lo completamente otro del hombre, Welte (1984), menciona: "Quien recuerda que todas las palabras humanas son finitas y no alcanza la infinitud de Dios, se volverá a Dios y en primer lugar enmudecerá" (p.191). Ya que, ante el misterio tremendo y fascinante, el hombre guarda silencio no sólo en actitud de asombro sino también para escuchar a Dios. Welte (1984) cita a Rudolf Otto, quien describe dicho encuentro como: "el misterium tremendum et fascinosum, lo que como fascinosum afecta enteramente al hombre y lo interpela, y lo que, al mismo tiempo, como tremendum, mantiene enteramente lejos de sí al hombre" (p.147).

Quizás, el silencio sea una de las actitudes más difíciles de lograr en la sociedad actual. Guardar silencio tanto a nivel externo como interno para escuchar a Dios eterno en la historia presente no es una tarea fácil, pero sí certera, en cuanto en ese mismo silencio el ser humano es capaz de escuchar sus búsquedas, deseos y anhelos más profundos y recobrar así el sentido de su existencia en la cotidianidad.

En el acontecer actual, con el ritmo atareado a nivel laboral, el silencio aparece como un sueño imposible de lograr. Por eso, la oración del silencio 
se presenta como una actitud radical que exige dar un salto al abandono de una nueva experiencia ante Dios, un paso inicial para un real encuentro con lo divino.

Si pensamos, la oración del silencio ha sido practicada y descrita por la tradición cristiana occidental, sobre todo por grandes místicos como: santa Teresa de Ávila, san Felipe de Neri, san Juan de la Cruz, santa Teresa de Calcuta, san Francisco de Asís, santa Teresita del niño Jesús. Ellos y ellas, son testimonio de esta oración del silencio, que les llevó a ser muy activos desde su contexto históricos eclesiales, interpelando el modo de vida cristiana y proponiendo un estilo de vida más fiel al evangelio. Esto nos permite observar que, la oración del silencio permite aly la creyente tomar una actitud orante que va adquiriendo tal fuerza y dinámica, que converge en el completo abandono a la voluntad de Dios; este abandono conlleva alegría, confianza, con miras al horizonte del Reino de Dios que le otorga pleno sentido. Por tanto, la oración del silencio no es una oración pasiva, sino completamente dinámica. El sólo hecho de que el o la creyente logre guardar silencio, ya es el gran movimiento que posibilita la contemplación, la escucha, y el conocimiento de Dios a través de su palabra. Dios por su parte, se muestra al creyente a modo humano y permite también que éstos se acepten a si mismo tal cual son. Es por eso que, la oración del silencio "Es la pura claridad del mirar, abierto a todo, sin ataduras" (Welte, 1984: 193).

Así mismo, la oración del silencio permite al creyente abandonarse en la presencia de Dios con todo su mundo, desde una perspectiva integradora, disponiendo a Dios la existencia completa. Y acogiendo en gratitud al Otro que es diferente en su fe, pues en la oración del silencio se puede comprender la forma de todas las demás religiones o espiritualidades, elemento que en la actualidad tiene mucha importancia para un camino hacia el ecumenismo y el diálogo interreligioso.

En este sentido, toda experiencia religiosa que cuida este aspecto vital en las diferentes religiones, guarda en sí el tesoro preciado de la religión, que es el espacio vital para el encuentro con el Dios de la vida, de la misericordia y la libertad de hijos de Dios. Si éste aspecto no se mantiene en las diferentes expresiones religiosas en la actualidad, ya sea a través de sus símbolos o ritos, entonces nos encontramos frente a una experiencia que se aleja de lo vital de la religión. Puede ser que se quedaron en la práctica vacía de sus ritos o centraron más la mirada en el rito, más que como medio, como un fin de la experiencia religiosa y esto sería una distorsión de la experiencia vital de la religión.

Esta crítica está dirigida a aquellas prácticas y comprensiones de Dios que se encuentran al interior de la religión y, que se muestran como verdad divina o como un mandato dictado directamente por Dios, pero que en su forma y en su fondo no corresponden a la religión. Esto, se debe a que hay prácticas aparentemente religiosas que ni en su esencia y tampoco como instrumento o medio para servir a Dios, apuntan al Dios de Jesucristo. Más bien, se encuentran en ellas, concepciones arraigadas de un falso dios, creado por el hombre para mantener poder, status, reconocimiento y admiración. Estas prácticas y concepciones erradas de religión, son sostenidas por una estructura de 
dominación del hombre y de la mujer que se presentan en su máxima distorsión, queriendo ser dios y presentándose como dios bajo estructuras aparentemente religiosas.

Para Schleiermacher (1990), esta realidad es el plagio vergonzoso que hemos entramado en nombre de Dios: “¿Cómo llegáis a hacer mención de esto, aun cuando no sea más que para refutarlo? ¿Por qué no habéis disuelto desde hace tiempo en sus partes y puesto al descubierto el plagio vergonzoso?" (p.31).

En esta misma línea, también podemos mencionar a Kant (1991), que en su obra La religión dentro de los límites de la mera razón, nos ofrece una vía para el pensar crítico que nos posibilita discernir dentro de los límites de la mera razón, la coherencia o incoherencia que existe al interior de la religión, especialmente en las prácticas que se desarrollan bajo el nombre del verdadero servicio a Dios. Para este autor, está claro que es la libertad ${ }^{23}$ del ser humano la que le posibilita ${ }^{24}$ que actúe de una determinada manera o no, al interior de la religión. Por lo tanto, en la perspectiva de un servicio a Dios en una Iglesia visible, responderá en la medida en que dicho servicio sea acorde a la iglesia invisible. En consecuencia, lo que salvaguardará el auténtico servicio a Dios para Kant (1991), es la intencionalidad de los mandamientos divinos:

El verdadero (moral) servicio de Dios, que los creyentes han de prestar como súbditos pertenecientes a su reino, pero no menos también (bajo leyes de la libertad) como ciudadanos del mismo, es ciertamente, como este mismo reino, invisible, esto es: un servicio de los corazones (en el espíritu y en la verdad), y sólo puede consistir en la intención de la observancia de todos los verdaderos deberes como mandamientos divinos, no en acciones destinadas exclusivamente a Dios (p.2).

Es decir, el hombre a través de la razón, tiene la facultad de observar si en sus máximas reina la intención de servir verdaderamente a Dios o es más bien una praxis con una intención de alcanzar sólo el propio bienestar.

Es así que Kant (1991), denuncia al clericalismo como uno de los principales modos de una praxis religiosa fetichista. Esto, dado que el clericalismo es entendido como la denominación, que designa sólo la autoridad de un padre espiritual por medio del concepto secundario de un despotismo espiritual, que puede ser encontrado en todas las formas eclesiales por muy modestas y populares que se anuncien, adquiriendo la significación de un vituperio.

Lo más visible a nuestros ojos críticos, es que se reconoce en ello una fe histórica, vista como provisional y cargada de representación simbólica y como el medio de promoción de una fe religiosa pura. En el fondo, en esta praxis religiosa como en otras que ponen su acento en un servicio a Dios, y que en sí no hace a ningún hombre mejor, porque su centralidad está en ciertas tesis estatutarias, o en recorrer ciertas observancias arbitrarias, convirtiendo al hombre en esclavo de sus propias leyes y, por tanto, en una praxis religiosa fetichista. 
En este contexto, la oración en silencio posibilita una praxis religiosa de una real comunicación con Dios, donde más que ritos y ropaje religioso, lo que importa es la disposición del corazón para comunicarse con Dios.

\subsection{La fe un paso vital para una experiencia religiosa}

Otro de los aspectos fundamentales en la experiencia vital de la religión que otorga sentido, tiene que ver con la respuesta del creyente en actitud de fe, puesto que la fe es una decisión personal que involucra la existencia completa. Por lo mismo, el significado más preciso de la fe está bajo la expresión del confiarse a Dios:

La afirmación de la fe es una afirmación bajo la modalidad de un confiarse a Dios. Con la palabra confiarse expresamos un movimiento transitivo, que parte de algo que dejamos atrás y desemboca en aquello a lo que nos confiamos (Welte, 1984: 180).

El confiarse a Dios significa abrir el espacio vital de la propia existencia finita para alcanzar aquello que se anhela. En este proceso de fe, el creyente se reconoce a sí mismo imposibilitado, ya sea por las miserias de la vida o por los quehaceres cotidianos que están siempre cargados de tensiones. Es así que, en estas experiencias de caducidad, la religión es un espacio real de acompañamiento en el proceso de maduración de fe, siempre y cuando posibilita a través de sus oraciones, vida comunitaria y celebraciones litúrgicas con un real encuentro con el Dios de la vida que es misericordia y gracia. Para los cristianos, por ejemplo, el abandono y la espera en Dios es en nombre de Jesús "esta es la fe en el sentido más pleno de la palabra, cuando Jesús nos decía que debíamos pedir al Padre en su nombre" (Welte, 1963: 33). El cristiano al creer en dicha palabra hace vida su fe en Jesucristo. Por lo tanto, el abandonarse en las manos del Padre, es una de las actitudes más cristianas porque se confía en la promesa de Dios en su Hijo Jesús:

En las manos de Jesús hemos de confiar todo nuestro corazón: ese corazón que, por encima de la vida y la muerte, no cesa de desear, esperar y pedir. A Jesús hemos de abandonarnos, como en la hora de la esperanza y del peligro nos confiamos únicamente a un buen amigo (Welte, 1963: 33).

En este sentido, la fe es un arriesgarse con toda la libertad ante el misterio abismal que es Dios. Esta libertad exige del abandono total de sí mismo, es decir:

El creyente se desliga seria y realmente de las manos de su propio cuidado de sí mismo, de su propia confianza, afirmación, anticipación disposición sobre síy de su propio subsistir en sí. Pero este proceso de desprendimiento serio de sí mismo para confiarse a Dios en la fe, sólo es adecuado a la situación fundamental religiosa si es total y no retiene nada de lo que el creyente es en sí, por sí y en su mundo. Pues ante Dios somos enteramente como somos. Ante el incondicionado no tiene ningún sentido plantear condiciones $\mathrm{y}$, con su ayuda, reclamar excepciones en la 
totalidad de la entrega exigida a Dios (Welte, 1984: 181).

Por lo tanto, la fe significa arriesgarse con toda la seriedad existencial que ello significa; es abandonarse en el conjunto de la existencia, por eso la fe religiosa es una fe arriesgada. Al respecto, es interesante mencionar varias formas de eludir la fe al interior de una experiencia religiosa: la primera forma de eludir la fe es que ante la fe no hay decisión en modo alguno; en otras palabras, la de no decir a Dios ni sí ni no. Esto significa que, no existe apertura para cuestiones fundamentales de la existencia como la pregunta por el sentido absoluto de la vida. Esta es una opción ambigua que se oculta en una falsa libertad basada en la coacción, sobre todo porque el creyente opta por los continuos quehaceres del mundo, es ahí donde finalmente coloca su seguridad y libertad; es un modo de negación oculta de la fe. Luego, una segunda forma de eludir la fe se encuentra bajo la misma forma de fe. Esta fe es interpretada y convertida en algo finito y disponible. "Es decir hacemos del misterio de Dios, un objeto palpable y disponible [...] Así la fe en Dios se transforma en la fe en nosotros mismos y en nuestra fuerza" (Welte, 1984: 50). Esta forma de fe es una incredulidad que guarda un peligro más oscuro, que es el fanatismo.

En ese reduccionismo del misterio de Dios a una realidad finita y manejable "surge algo así como una violencia para imponer de una manera $a b-$ soluta esa nuestra medida humana, y por tanto, limitada y para elevarla por encima de cualquier otra medida y por encima de todas las consideraciones" (Welte, 1984: 51). Lo más delicado de esta pretensión, es que en el fanatismo religioso el derecho de Dios se convierte en el derecho del hombre. "Y la fe en Dios se transforma en la fe en nosotros mismos y en nuestra fuerza" (Welte, 1984: 50).

Luego, la tercera forma de incredulidad es la que adopta la forma de un rotundo no a Dios, por lo tanto, es una sublevación abierta del no querer creer en Dios, la ventaja de esta actitud es que ella es clara y no oculta nada.

Después de mencionar tres formas concretas de eludir la fe en el proceso de una experiencia religiosa o espiritual, cabe recalcar que, la fe requiere soltar las propias represiones, debido a que creer en Dios implica discernir ${ }^{25}$ entre bien y mal, entre verdad y mentira, a lo que Welte (1984), destaca:

Porque el creyente cree en Dios, cree en Él también como juicio, y también como gracia. Quien, por tanto, cree en Dios, tomará el bien como lo bueno y, por otra parte, también el mal como lo malo, manteniendo con todo rigor esta diferencia (p.185)

En este sentido, la experiencia religiosa no puede provocar daño alguno al creyente que se encuentra en este proceso de búsqueda y camino de fe, por el contrario, debe ser un espacio de dialogo y sostén. Por otra parte, un proceso de fe nunca conllevaría a una praxis de esclavitud, sino que el camino de abandono a Dios conlleva necesariamente una experiencia vital de libertad, que posibilita crecer en la propia identidad del creyente y no en la homogenización. 
Confiarse a Dios significa afirmarlo en la realidad concreta con la propia existencia, significa que la vida misma se abre en dirección hacia las esperanzas del Resucitado y con Él, la existencia hacia lo inconmensurable, ya que la existencia comienza a dirigirse a través de la fe en Él: "más allá de todo lo comprensible y esperable la fe no querrá retener nada en manos de su propia representación" (Welte, 1984: 183). Por lo mismo, el creyente que ha dado el paso de fe, es un real testimonio de su experiencia de encuentro con Dios porque está atento al espíritu del Resucitado para escuchar y ver la novedad de Dios actuante en la historia. Por eso Welte (1984), menciona que la fe es percibir y afirmar a Dios en la historia desde un compromiso que abarca la existencia entera.

En este camino de fe, tanto el creyente como la visión que él tiene de Dios, se irán transformando en aquella relación personal que ha confirmado su existencia, como una vida que puede desarrollar con persistencia la vida creyente y dar a la existencia pleno sentido en relación a Dios.

En la persistencia de la historia puede el creyente acrisolar su lealtad, desde luego es esencial a su fe. Y puede así mismo acreditarse la comunidad, en la que cada uno ha de estar dispuesto a asistir al otro. Así a través del tiempo la fe puede crecer y aguardar. Crecer en fidelidad y paciencia y aguardar la mayor fidelidad a Dios, la cual se ha manifestado para siempre en Jesús. La fe reunirá las aportaciones de esa espera, en sus diversas formas y modalidades, para acabar entregándolas todas al misterio eterno. (Welte, 1984: 96)

\subsection{El sentido de los cristianos es vivir en Espíritu y en verdad}

En este artículo se ha reflexionando sobre cómo la religión otorga sentido a la existencia del hombre. En este último apartado se centrará la mirada en cómo el sentido de los cristianos es vivir en Espíritu y en verdad.

Pero ¿Qué significa vivir en Espíritu y en verdad?, para la perspectiva cristiana, es vivir en la vida nueva que se alcanza en Jesucristo. Esta vida nueva es la promesa que hizo Jesucristo al Resucitar, desde este momento, Él invita a cada cristiano a participar de una vida en su Espíritu:

Por eso, lo que al Señor le interesa al fin de cuentas es comunicar su Espíritu a los suyos. Ellos en la fe, habían comenzado a convertirse en íntimos y en amigos. Tenían necesidad, por tanto, de entrar en la comunión del Espíritu, y con ello debían experimentar cada vez más en sí mismos la animación santa de la que el Señor vivía (Welte, 1963: 14).

Esta vida interior en el Espíritu, es la vida en Jesucristo, que posibilita un proceso hacia una vida en la libertad de los hijos de Dios y de un Espíritu vivo, y se mueve en medio de su Iglesia para renovarla y fortalecerla en la auténtica palabra del Resucitado. Aquí, reside el alma entera del cristianismo, que el Espíritu de Jesús permanezca y se mueva en medio de su Iglesia de un modo concreto, encarnado y visible. 
A pesar de que en el contexto actual muchas veces no se pueda ver dicho Espíritu de vida y renovación, lo importante es confiar y dejar que el don de Dios despierte y brote en cada persona que lo busca incesantemente, posibilitando que un nuevo retoño nazca del tronco viejo (Is. 11, 1-9), que del tronco viejo de las propias miserias institucionales y eclesiales den cabida a lo nuevo de Dios en la Historia. Esto consiste, en primer lugar, en vivir en la sintonía del Espíritu del Resucitado; para discernir y trabajar en la voluntad del Padre, con paciencia, perseverancia y con la humildad suficiente para reconocer las propias faltas que permitirán también vivir en el Espíritu de la verdad (Jn. 16,13); y en segundo lugar en la búsqueda de aquella verdad que en su fondo más hondo guarda nuestra existencia y que anhela sin cesar la benevolencia plena de Dios como donación.

Es así que, la verdad del Espíritu conducirá primero a la verdad del propio corazón, y “dará valor para desgarrar la red de imaginaciones en la cual nos estamos enredando contantemente casi sin darnos cuenta. Nos dará valor de ser lo que efectivamente somos" (Welte, 1963: 64).El Espíritu de la verdad permite mirarnos de frente a Dios con la verdad confesada que posibilita abandonarnos para alcanzar así la libertad de los hijos de Dios.

Por eso, el camino de los cristianos es vivir en Espíritu y en verdad, este camino del Espíritu que comenzará a disipar toda rigidez y dureza, toda complacencia en sí mismo y todo orgullo estéril. Este es el Espíritu de los cristianos, el cual hace necesario despertar en los contextos de máxima miseria y delito al interior de la institución eclesial. El Espíritu de verdad, que con sus llamas inquietantes y purificadoras nos renueva desde el fondo de nuestra vida. Que como soplo derriba todo lo enmascarado y falso, todo poder humano que falsea a Dios y falsea a los cristianos. Sólo este poder divino que es fuerza renovadora permite a los cristianos la unidad para buscar la verdad suprema y la justicia evangélica. Este Espíritu se nos ha sido dado, pero es necesario restablecer la fe y confiar en su fuerza renovadora.

\section{Desafíos y Perspectivas}

En el contexto de una gran crisis religiosa institucional es necesario en primer lugar, asumir la crisis de sentido que se vive al interior de la religión desde un contexto sociocultural más amplio. Pierre Bourdieu, ha desarrollado la idea que la religión ha sido capaz de crear ciertos espacios donde se estructura la dominación simbólica a través de representaciones compartidas y ciertas dinámicas del poder. Esta estructura se reconoce como institución religiosa que en la Iglesia Católica por ejemplo se ve en una estructura formal que es burocrática, jerarquizada y con funcionarios. En ella existe una constante tensión entre la revitalización y la institucionalización.

Ahora, debemos ser conscientes que la crisis institucional religiosa responde también a la crisis institucional contemporánea. Ésta, tiene nuevos elementos como el "reforzamiento de la subjetividad individual, de los derechos y preferencias del ciudadano" (Estrada, 2006: 206). Se le suma a ello un rechazo cultural a las instituciones, ya que son vistas como organizaciones que limitan la libertad individual como también hay "una 
profunda crítica a las dogmatización de estructuras, organizaciones y formas de autoridad que se presentan como inmutables y queridas directamente por Dios, ignorando su historicidad, su origen eclesial y las grandes transformaciones vividas en su proceso de constitución" (Estrada 2006: 264).

Por lo mismo, se reconoce que, la desinstitucionalización o la crisis institucional religiosa, responde también a un proceso más amplio de resquebrajamiento de las estructuras sociales que no dan sentido a la existencia de la sociedad actual. Este resquebrajamiento también desentrama el hecho religioso que ha formado parte de la cultura y la sociedad en Latinoamérica, una enseñanza religiosa en que la religión cristiana entró al continente en nombre de la civilización de modo muy poco civilizado.

Ahora, si pudiéramos definir una de las principales características del cambio de la religiosidad en la época actual, lo describiríamos en términos de Thomas Luckmann (1997):

En la medida en que las sociedades se modernizan, las formas religiosas institucionalizadas decaen y la experiencia religiosa tiende a refugiarse en el espacio propio de la esfera privada. El modelo religioso institucionalizado tiende a convertirse en una retórica vacía, y el creyente religioso se ve inclinado a formar por su propia cuenta un cosmos sagrado (p. 63).

Esta, nos parece una definición bastante elocuente de lo que ocurre a nivel global respecto de la religión, ya que uno de los análisis que la sociología propone en la actualidad, es la creciente desinstitucionalización como efecto del debilitamiento o desaparición de los elementos fundamentales de la institucionalización que son la cristalización de las normas de comportamiento, las pautas y valores de sentido y el control social mediante la regulación moral normativa. Esto, porque la religión institucional ha sido incapaz de dar respuesta a las experiencias cotidianas del individuo, lo que ha provocado un traslado de las necesidades de sentido trascendente a otros espacios. Por lo mismo, existe a la par del creciente proceso de desinstitucionalización nuevos modos de creer en los que se reconoce: el fundamentalismo, los nuevos movimientos religiosos ${ }^{26}$ o neo espiritualidades fruto de ello, el sincretismo.

Desde la visión de la religión ${ }^{27}$ cristiano Católica, tanto la crítica de la religión como la crítica a la religión ${ }^{28}$, han aportado bastante, mencionando los núcleos que provocan dicha crisis de sentido (Fliche, Martin y Santos, 1978). Un gran ejemplo de ello, fue la reflexión que se realizó, en torno a la reforma ${ }^{29}$, que resultó ser un modo evidente de acoger las causas de discusión que han dado pie para grandes momentos de reflexión teológica y cambios en la praxis cristiana; siempre con la inquietud y búsqueda de vivir más acordes al evangelio.

En este contexto, la pregunta por el sentido que otorga la religión en la sociedad actual, se manifiesta como una pregunta auténtica y radical, en la cual, como hombre y mujer creyente, se puede asumir responsablemente el destino cristiano, buscando así, un horizonte que posibilite vivir de 
un modo más humano, en que la vida cristiana no esté disociada con la vida social o familiar, sino que sean una vida asumida en su conjunto en sintonía con el evangelio y en donde estén las posibilidades del pensar crítico, así como también de abrir la puerta a la esperanza radical de la existencia humana.

De esta forma, es necesario dar paso a un horizonte que posibilite la pregunta por Dios, sin negarla de hecho, un espacio en el cual la persona recobre la libertad que posibilita decidir por la vida que realmente quiere construir. Pero también, es preciso cerrar espacios a estructuras tramposas, a sistemas de poder que engañan y limitan la comprensión de ser humano que existe en ciertos sistemas religiosos a través de la pretensión de poder y de absolutez.

Es imprescindible dar lugar a un futuro en el cual el hombre y la mujer sean capaces de encontrar la verdad de su existencia, que puedan levantar la mirada hacia la posibilidad de la eternidad, sin temores esclavizadores, sin condenas, sino dejando aflorar la esperanza existencial del encuentro con el Tú eterno. Un horizonte en que el hombre y la mujer aprendan a despojarse del ropaje viejo, que es la angustia existencial que les atormenta, las falsas promesas escatológicas, los falsos dioses, los falsos servidores de Dios. Despojarse para abrir los brazos a un horizonte tan humano que, de espacio a lo divino, porque lo más humano es lo más divino de Dios en la historia.

Hoy día, plantear la pregunta de cómo la religión otorga sentido en la actualidad, es abrir un camino al creyente, que sabrá reconocer lo que oscurece la verdad de Dios y los caminos que conducen a la resucitada esperanza, y a las sendas de vida, que son impulsadas por el Espíritu Santo que guía una y otra vez hacia la vida en Dios. Asumir este camino, es caminar con todo lo que él significa, despejando los sistemas de antaño que han oscurecido a lo esencial de la religión y abrirse al discernimiento comunitario que se alimenta de la palabra viva que es Jesucristo.

\section{Referencias citadas}

Bentué, A. (2004): Dios y dioses. Santiago de Chile, Ediciones Universidad Catolica de Chile, pp.30-162.

Berger, P. y Luckmann, T. (1997): Modernidad, pluralismo y crisis de sentido. La orientación del hombre moderno, Barcelona, Paidos.

Blondel, M. (1893): La acción. Ensayo de una crítica de la vida y de una ciencia de la práctica, Madrid Biblioteca de Autores Cristianos.

Estrada, J. (2006): El cristianismo en una sociedad laica. Cuarenta años después del Vaticano II, $2^{\circ}$ edición, Bilbao, Desclée de Brouwer.

Ferrater, J. (1958): Diccionario de filosofía, Buenos Aires, Editorial Sudamericana.

Fliche, A., Martin, V. y Santos, A. (1978): Historia de la Iglesia. Vol V, Valencia, Edicep.

Floristán, C. (2002): Nuevo diccionario de pastoral, Madrid, San Pablo.

Gesché, A. (2004): El Sentido. Dios para pensar, VII, 
Salamanca, Sígueme.

Heidegger M. (2007): El ser y el tiempo, Buenos Aires, Fondo de Cultura Económica.

Izquierdo, C., Burggraf, J. y Arocena, F. (2006): Diccionario de teología, Navarra, EUNSA.

Kant, I. (1991): La religión dentro de los límites de la mera razón, Madrid, Alianza Editorial.

Latourelle, R. y Fisichella, R. (1990): Diccionario de teología fundamental, Madrid, San Pablo.

Martínez, A. y Cortés, J. (1996): Diccionario de filosofía en CD ROM, Barcelona, Herder.

Pacomio, L. (1983): Diccionario teológico interdisciplinar, Salamanca, Sígueme.

Santidrián, P. (1993): Diccionario básico de las religiones, Navarra, Verbo Divino.

Schleiermacher, F. (1990): Sobre la religión, Discurso a sus menospreciadores cultivados, Madrid, Tecnos S.A.

Silva, J. (2011): “Algunos rasgos de la ontología de la historia propuesta por Bernhard Welte y sus desafíos para la teología”, Teología y vida, [online] 52(3), pp.527-553.

Disponible en: https://scielo.conicyt.cl/scielo.php?script=sci_arttext\&pid=S0049-34492011000200009.

Welte, B. (1963): El Espíritu, vida de los cristianos, Madrid, Eds. Fax - Colección Perspectivas.

Welte, B. (1984): ¿Qué es creer?: Ideas para una filosofía de la religión, Barcelona, Herder.

\section{Notas}

1 Bernard Welte es reconocido por su pensamiento agudo y una propuesta teológica coherente y dialogante, que sin lugar a dudas es un gran aporte a la problematicidad actual. En esta línea, el teólogo y filósofo alemán ha desarrollado su pensamiento en una perspectiva de la filosofía de la religión, que posibilita pensar cómo la religión da sentido a la existencia del hombre. Por tanto, sabe responder a los desafíos actuales en los que se encuentra la religión; ya que también integra la importancia del rol de la historia en el encuentro de Dios con el hombre. Teniendo en cuenta el punto anterior, el artículo recoge parte de una reflexión mayor que tiene en cuenta la obra de B. Welte "Filosofía de la religión" (1982) y como obra secundaria "¿Qué es creer? Ideas para una filosofía de la religión” (1984). Luego en las obras “¿Qué es creer? Ideas para una filosofía de la religión” (1984).

2 “Sentido GEN:(del latín sensus, de sentire percibir por los sentidos o por la inteligencia). Tiene sentido lo que es capaz de ser percibido por los sentidos o por la mente; propiamente lo que puede ser comprendido. La ciencia en general no es otra cosa que una comprensión o interpretación (de las regularidades de los fenómenos) del mundo; y el lenguaje-«mundo» de los signos- no es sino un sistema de signos, de los cuales se estudia su significado. La clásica «pregunta por el sentido» se dirige, no hacia los fenómenos del mundo ni hacia los signos del lenguaje, sino propiamente a cosas, conjuntos de cosas o procesos poco susceptibles de ser tratados científicamente, como, por ejemplo, el mundo en su conjunto, el hombre, la vida, la historia, la muerte, etc. Para estos casos, se percibe sentido si 
cada una de estas cosas puede ser inscrita en una serie ordenada de causalidades (que explican su razón de ser), o de finalidades (que explican su relación a un fin); si hay para todo ello respuesta a las preguntas ¿por qué? o ¿para qué? La pregunta por el sentido de algunas de estas cosas puede constituir un problema filosófico"

3 Francisco Romero reconoce "que hay una secreta afinidad entre los diversos significados de sentido. Tanto es así que cualquier dilucidación sobre el sentido se ve obligada a poner de manifiesto casi al mismo tiempo la unidad y la variedad de sus significados".

4 "Sólo en época relativamente reciente se ha investigado el problema del sentido como una cuestión separada, lo usual era antes confundir el ser y el sentido y considerar que la mención de uno implicaba necesariamente la referencia a otro. Así, para la metafísica que podríamos llamar "tradicional”, lo que se consideraba como "el ser" era a la vez lo que poseía sentido de éste equivalían aproximadamente a la misma cosa".

5 "La investigación fenomenológica sobre el sentido ha permitido, en cambio, no sólo poner entre paréntesis la mentada identificación, sino inclusive considerar como relativamente separados los distintos significados del término "sentido". Por lo pronto, se ha estimado que el sentido no puede sin más confundirse con la significación de un término o de una proposición".

6 La dirección "a su vez, constituye una de las formas esenciales del mundo del espíritu en sus dos formas: subjetivo y objetivo. El primero poseería por sí mismo, como totalidad y estructura, un sentido, pero además haría referencia a sus objetivaciones, determinadas por los valores y tendría, en última instancia, un sentido en virtud de estos valores".

7 Esta palabra sólo surge en elámbito del descubrimiento moderno del sujeto con Kant. A lo que ahora se llama «sentido de la vida», «sentido de la existencia», correspondía anteriormentelaidea de «finalidad», «ordenación a una meta», fin. Del futuro pasa el acento al presente con la fórmula: «Valor de la vida», usada por primera vez en 1792 por D. F. Schleiermacher (Über den Wert des Lebens, 1792-1793). Con acentuación metafísica, hermenéutica o sociológica, la palabra recorre toda la filosofía moderna hasta Heidegger, hablando del «sentido del ser», Wittgenstein situándolo como problema lingüístico y Blondel plantándolo en el pórtico de su obra como el problema por antonomasia: «¿Sí o no? ¿Tiene la vida humana un sentido y el hombre un destino?"

8 El concepto que utiliza Welte, lo formuló apoyándose del concepto de Heidegger de su obra Ser y tiempo “Estar-en-el-mundo" Pero también del pensamiento de Santo Tomas de Aquino en la Summa Teologiae I, q78, a.1 y De Veritatis, q 1. a. 1. Véase más en: B. Welte, Comprensión de salvación, Investigaciones filosóficas de algunos supuestos para la comprensión del cristianismo. (Traducción de César Lambert Ortiz) Talca, 2008) 55. cita a pie de página 29. Por otra parte, “el análisis del «ser ahí» no es sólo incompleto, sino por lo pronto también provisional. Se limita por el momento a poner de relieve el ser de este ente sin hacer la exégesis del sentido de este ser. Su misión es preparatoria para poner en libertad la interpretación más original posible del ser. Una vez ganado este horizonte, pide la analítica preparatoria del «ser ahí» que se la reitere sobre la base más alta y propiamente ontológica. Como sentido del ser del ente que llama- 
mos «ser ahí», se muestra la «temporalidad». Que es así, tiene que comprobarse en la exégesis reiterada, de las estructuras del «ser ahí» señaladas provisionalmente, como modos de temporalidad. Pero con esta interpretación del «ser ahí» como temporalidad no queda aún dada la respuesta a la pregunta directiva, que interroga por el sentido del ser en general, aunque sí queda preparado el terreno para obtener esta respuesta.

9“Una definición descriptiva de religión. Según la bien conocida etimología que da Cicerón del término, la palabra latina religión se deriva de re-ligere, que significa "estar atento, considerar y observar, mantenerse vivos", es decir religión significa el cumplimiento consciente del deber, temor de un poder más alto. El apologista tardío Lactancio (ca. 260-340 d. C.) creía que la palabra derivaba de re-ligare, que significa "atar, mantener junto", una relación estrecha y duradera con lo divino. El hombre está atado por Dios por medio de la religiosidad. Desde este punto de vista la religión es un hecho que entra en el dominio de la interioridad y del sentimiento humano. Aunque no existe certeza de la exactitud de estás derivaciones, la última fue adoptada por san Agustín y dominó los puntos de vista teológicos de la edad media. Ambos significados se pueden integrar para indicar el doble aspecto de la religión, a saber: la dimensión objetiva y subjetiva de la experiencia religiosa [...]. La palabra religión tuvo su origen en el lenguaje pre-cristiano, pero entró en el uso lingüístico cristiano, tanto en la versión latina de la Biblia (La Vulgata) como en los escritos de los padres de la Iglesia latinos. En la cristiandad medieval, religión en su grado supremo y más grande, significa vida monástica, con los tres votos de pobreza, castidad y obediencia. De ahí que el religioso por excelencia fuese el monje o monja, y el estado religioso fuese considerado el estado de perfección. La religión incluye no solo las creencias, costumbres, tradiciones, y ritos que pertenecen a agrupaciones sociales particulares; implica también experiencias individuales. Toda concepción que acentúa el aspecto comunitario de la religión hasta la exclusión de la vida psíquica del individuo es defectuosa, puesto que es la aprehensión personal por el individuo de lo sagrado o lo divino lo que constituye uno de los más importantes rasgos de la religión. Según J. Frazer, la religión “es una propiciación o conciliación de poderes superiores al hombre que se cree que dirigen y controlan el curso de la naturaleza y de la vida humana. Así definida, la religión consta de dos elementos, uno práctico y otro teórico, a saber: una creencia en poderes superiores al hombre y un intento de propiciarles o agradarles". Explica después que "la creencia viene claramente en primer lugar, ya que debemos creer en la existencia de un ser divino antes de que intentemos querer complacerle. Pero a no ser que la creencia conduzca a la correspondiente práctica, no es una religión sino sencillamente una teología.

10 Solo por mencionar algunas áreas de estudio especializado: Filosofía de la religión, teología de las religiones, fenomenología de la religión, fenomenología histórica de las religiones, critica de la religión, psicología de la religión, sociología de la religión, entre otras.

11 Con el término animista posteriormente se refiere a religiones primitivas triviales. Con esta denominación nos referimos a la religión de los 200-300 millones de habitantes que integran las tribus de América, Asia, Oceanía. Sus creencias y formas religiosas son distintas a las religiones prehistóricas del Paleolítico y del Neolítico, aunque también tengan algunos rasgos de 
semejanza. En el siglo pasado de las denominó religiones animistas, espiritistas o simplemente supersticiosas, sin concederles las categorías de religión. Hoy se les llama religiones primitivas para distinguirlas de las grandes religiones como el cristianismo, judaísmo e islamismo. Son religiones no literarias porque dependen de los mitos, otro rasgo es que creen en los espíritus muertos y honran a los espíritus ancestrales. Las tribus o pueblos son guiados por chamanes, herboristas, curanderos, adivinos.

12 El término judío, proviene directamente del nombre del patriarca Judá, el cuarto de los hijos de Jacob. Es así que Josué asigno dicho nombre a la tribu que penetro la tierra prometida (Js. 15). Además, a ello se suma el significado etimológico primero de la palabra Judá que viene de la raíz Jahjudí que significa el que conoce a Yahvé (Gn 29,35). Así la originalidad del pueblo judío es la confesión de ese conocimiento de Dios como el único Dios y señor, tomando su forma más clásica en el credo judío: Shema Israel.

Es así que el judaísmo se caracteriza por sus tradiciones ancestrales vinculadas a la experiencia del Dios de las promesas que funda el cumplimiento de las cláusulas de la alianza, luego sus innumerables enseñanzas rabínicas recogidas en el Mishná y el los dos Talmudes anteriores. También se desarrolla toda una tradición profética.

13 "Para el trabajo de esta tesis, mencionaremos a modo muy general sus características ya que en uno de los capítulos realizaremos un desarrollo más profundo de lo que significa el cristianismo en su esencia. La característica principal del cristianismo, radica en la inédita experiencia espiritual de su fundador Jesús de Nazaret, quien reinterpretando el significado judío de las promesas realizadas por Dios a los padres de
Israel. Ello fue con una profundidad insospechada sobre todo por su vida, obra, muerte y Resurrección. Lo que permitió que quienes le conocieron y siguieron lo reconocieron como el Señor, convirtiéndose así en apóstoles y testigos del Resucitado. La fe es en Dios uno Trino. Padre-Hijo- Espíritu Santo. Luego el impacto de la experiencia de Pablo de Tarso fue fundamental para la expansión del cristianismo, y las posteriores relecturas de los acontecimientos vividos con Jesucristo permitieron que el cristianismo se consolidará".

14"El término Islam significa sumisión, en el sentido de sometimiento a Dios. El Islam se concibe como una religión natural, para la que todo ser creado existe en dependencia de Alá, obedece a su poder creador y vive para adorarle. Tiene una pretensión universal". Así mismo encontramos que: "El Islam se concentra en cinco creencias fundamentales, a las que corresponden cinco pilares que constituyen las obligaciones básicas del musulmán practicante: Monoteísmo estricto, La Umma (interés por que la comunidad sea universal. Constituida por todos los creyentes y sometidos a la voluntad de Alá), fe en la justicia divina (Alá omnipotente u omnisciente acompaña siempre a sus fieles en la vida. Castigando a los infieles y a quienes se oponen a su voluntad soberana), La providencia (Alá todo lo sabe y prevé) y el juicio final. Luego los cinco pilares son: Sajada (postrarse en oración), Hajj (obligación de una peregrinación al santuario de Kaaba, en la Meca), Zakat (limosna), Salat (plegaria ritual islámica prescrita para ser recitada cinco veces al día), Saum (Ayuno del mes).

15 El Hinduismo es más un conjunto de religiones que una religión propiamente dicha, así se entiende por Hinduismo el conglomerado o amalgama de diversos cultos y creencias dentro de un marco común de castas 
que viven en la India. Supone, una combinación de la religiosidad védica, brahmánica, de los Upanischads, junto con formas religiosas nacidas en el valle del Indo.

16 Su doctrina se contiene básicamente en el llamado sermón de Benarés. Y en la tradición confiada a la memoria de sus discípulos durante 200 años y codificada después en los textos o escrituras del tipitaka. La historia del budismo comienza con Buda y sus cinco discípulos que difunden su doctrina por todo el continente asiático y Oceanía. Sus seguidores forman comunidad de monjes (sangha) y laicos que pretenden seguir al maestro dentro de las numerosas corrientes o escuelas de interpretación de su doctrina.

17 El ámbito de lo sagrado no es una realidad, ni un conjunto de realidades, no es una zona de lo real ni un acto determinado, ni un conjunto de actos. Es una forma peculiar de ser y de aparecer el ser humano y la realidad en su conjunto que surge justamente cuando aparece lo religioso.

Además, podemos decir que: "Lo sagrado es un término central en la religión, es aquel orden o ámbito de la realidad en que se inscriben los hechos religiosos particulares y se constituye en el horizonte complexivo en el cual madura la experiencia religiosa. Fenomenológicamente lo sagrado está delimitado por signos que advierten un tránsito desde lo ordinario hacia la esfera que es y hace ser de otra manera. El signo de ruptura de nivel más poderoso está constituido por la experiencia de lo numinoso como núcleo de lo sagrado y que se muestra como "mysterium tremendum et fascinans".

$18 \mathrm{El} \mathrm{misterio} \mathrm{se} \mathrm{presenta} \mathrm{en} \mathrm{el} \mathrm{hecho} \mathrm{religioso,} \mathrm{en} \mathrm{la}$ relación del sujeto frente a una realidad que es extrasubjetiva y es calificado como una realidad suprema- lo numinoso- lo místico- el misterio que ostenta una realidad de trascendencia.

19 Trascendencia que en lenguaje religioso quiere decir, lo totalmente otro, la elevación por encima de todo, la supremacía en el ser y el valor, superior (summo meo), la inaccesibilidad para el hombre.

20 "El hecho religioso se concreta en las diversas religiones históricas de la humanidad. Brota de una experiencia humana, originaly primaria, de relación con una realidad suprema”.

21 En la hierofanía, el discurso sobre lo santo en su manifestación describe noéticamente aquella unidad contrapuesta conformada por actos que permiten que lo santo sea experimentado como presente al modo de sustraerse, como invocado bajo la forma de innombrable y como quien reta a los hombres bajo la forma de irrealizable.

En este sentido M. Eliade ha sido uno de los que ha aportado más desde esta perspectiva ya que pretendía aferrarse al principio fundamental de la filosofía de la religión, según el cual el acto y el objeto religioso sólo pueden describirse correctamente en estricta correlación mutua, es decir en la dialéctica de lo sagrado mismo y no en un fundamento extra-religioso sino en la dialéctica de las hierofanías. Precisamente la coherencia con la que $\mathrm{M}$. Eliade ha recorrido su itinerario intelectual puede ser un ejemplo de cómo el análisis de las hierofanías, en su unidad de mostrarse y sustraerse, ha de conducir inevitablemente a una consideración histórica de las religiones.

22 "Del latín oratio que significa lenguaje, discurso. Algunos ponen su etimología en osoris (boca). En algunas lenguas modernas el término principal y 
más frecuente para designar este trato con Dios ha quedado ligado a prex, esto es, a la idea de pedir (priere en francés); en castellano, en cambio el término principal es oración, que refleja de modo más completo que petición la naturaleza del acto”. Por otra parte, se puede afirmar que: "En todas las religiones tanto primitivas como históricas encontramos múltiples formas de oración o de comunicación del hombre con Dios, o con seres espirituales. Admite innumerables formas y clases, como oración pública (culto público) y oración privada (culto privado). Tanto una como otra pueden ser oración de súplica, alabanza, arrepentimiento, petición, cada una de las cuales asume distintos estilos y estructuras. Así mismo: “De un modo u otro la oración se da en todas las religiones, pero solo se puede hablar de oración con propiedad donde se reconoce la verdad de un solo Dios personal y trascendente que se ha manifestado al hombre, y la verdad sobre el hombre mismo, varón o mujer, como persona libre creada por Dios e invitada al dialogo con Él. (cf. G.S. 19). Esta verdad resplandece plenamente en Cristo. Por eso la fe cristiana constituye el fundamento más perfecto de la oración"

23 Ya que por el libre albedrio, el hombre se construye una máxima que posibilita el desenlace de sus decisiones y acciones. Esta puede ser una máxima que tiende al bien o una máxima que tiende al mal. En definitiva, el hombre no nace determinado por su naturaleza, sino que tiene la libertad de elegir. Así las leyes, que su máxima obligan, deben ser a la vez una forma de la legalidad universal, es decir, al momento de que tengamos una máxima, ésta será válida en la medida que sea universal. Ya que la ley moral del seguimiento del deber es en general una sola, única y universal

24 Kant salvaguarda la libertad del hombre, com- prende al hombre como un ser moral y por tanto libre y responsable de sus actos. Es así como desarrolla los cimientos de su pensamiento bajo la ley moral, que constituye al hombre un ser moral.

25 Welte en este sentido nos advierte que "será difícil trazar la línea del límite. En todo caso el mal es lo queno debe ser, visto primero desde Dios y luego desde el hombre. Es lo que ha sido juzgado y superado y lo que debe ser perdonado cuando rebrota. Tomar en serio el mal en el sentido de la fe significa, pues, negarlo $\mathrm{y}$ hacer todo lo posible para trocarlo en bien. El mal es por sí mismo lo negativo, lo que debe superarse y cambiarse en bien".

26 Y los nuevos movimientos religiosos nacen en la modernidad siendo denominados por la sociología francófona como nebulosa neo esotérica y que hoy se conoce como New Age. Algunos expertos mencionan que este modo de religiosidad responde a la cultura de consumo que crea la necesidad de consumo religioso.

27 Se refiere a la crítica moderna de la religión en las cuales encontramos a Immanuel Kant (Critica de la razón pura, critica de la razón práctica); Bertrand Russell (El miedo); Ludwig Feuerbach (La religión como proyección del hombre, La esencia del cristianismo); Karl Marx (La religión como expresión de la miseria real, Trabajo asalariado y capital); Sigmund Freud (La religión como huida de la dura realidad); Jean Améry (gnosticismo, Más allá de la culpa y la expiación)

28 Es decir, la crítica interna a la religión dónde se reconoce a los Profetas, las denuncias y críticas que realizó Jesús el Hijo de Dios, y las críticas de diferentes reformadores que han aportado a través de la historia. Podemos mencionar en este sentido también la refor- 
ma Monástica, que se inició en el Concilio de Aix-la Chaplle, donde se presentaron 83 artículos con la intencionalidad de implantar una observancia uniforme en todos los monasterios del imperio Franco., esto fue solo en comienzo de un largo camino reformador. También se destaca la reforma protestante con: Lutero, Zuinglio, Calvino. Que dio inicio al Concilio de Trento (1518-1534). Como también hubo hombres y mujeres que impulsaron reformas internas, destacan entre ellos San Francisco de Asís, Teresa de Ávila.

29 "La Reforma como hecho global de Europa es anterior, en cada área espiritual tiene sus determinaciones y en España tenía ya cuarenta y cinco años de puesta en marcha antes de que en 1517 estalle el fenómeno de Lutero. Por eso las terminologías pueden oscilar. Se puede hablar de Pre-reforma, Reforma y Contra-reforma. Otros hablarán de Reforma General, de Reforma protestante, de Mística Católica. Incluso en alemán existen dos palabras: se habla de Reforma en sentido generaly de Reformation, que se refiere explícitamente al fenómeno desencadenado por Lutero. Hay que comenzar clarificando que la Reforma Católica es un hecho que surge en los últimos decenios del siglo XV en 1470, que tiene un enorme despliegue, que tiene una lógica propia y que a partir de los años treinta, inexorablemente, va a estar condicionada por el hecho de Lutero y, a partir de 1559, 1560, se va a convertir de forma explícita en un fenómeno de reacción frente al luteranismo". 